\title{
The application of genetics methods to differentiation of three Lactobacillus species of human origin
}

\author{
Tomasz Gosiewski • Agnieszka Chmielarczyk • \\ Magdalena Strus • Monika Brzychczy-Włoch • \\ Piotr B. Heczko
}

Received: 11 July 2011 / Accepted: 22 November 2011 / Published online: 10 December 2011

(C) The Author(s) 2011. This article is published with open access at Springerlink.com

\begin{abstract}
In recent decades, the interest in probiotics as diet supplements or drugs has increased. In order to determine a specific bacterial isolate to be probiotic, it is necessary to describe precisely its probiotic characteristics and taxonomic properties, including the strain level. Most of the well-known genotyping methods were designed for the commonly-found pathogenic bacteria. The objective of this study is to undertake an attempt at standardization of FISH, RAPD and PFGE methods to genotype and identify the bacteria belonging to Lactobacillus fermentum, L. gasseri and L. plantarum species. The FISH probes have been designed and tested for Lactobacillus fermentum, L. gasseri and L. plantarum species and an endeavor has been made at standardization of RAPD and PFGE methods for these bacterial species. Moreover, the MLST method was applied to differentiate Lactobacillus plantarum strains. L. plantarum isolated from humans could not be genetically diversified with the use of RAPD, PFGE or MLST methods; only the strains originating from plants have displayed diversification among themselves and have been different from the strains of human origin.
\end{abstract}

Keywords Lactobacillus · FISH · RAPD · PFGE · MLST

T. Gosiewski $(\bowtie) \cdot$ A. Chmielarczyk $\cdot$ M. Strus $\cdot$

M. Brzychczy-Włoch • P. B. Heczko

Chair of Microbiology, Jagiellonian University Medical College,

18 Czysta Str.,

31-121 Cracow, Poland

e-mail: tomasz.gosiewski@uj.edu.pl

\section{Introduction}

In the last recent decades, the interest in probiotics as diet supplements or drugs has increased. According to their definition, probiotics are live microorganisms which have a beneficial influence on the health of the host when administered in adequate amounts. They are mostly applied as preparations for restoring the ecological balance of the gastrointestinal and genital tracts. Pursuant to the assumptions of the report of the Joint Working Group of Food and Agriculture Organization of the United Nations concerning preliminary guidelines for the evaluation of probiotics, it has been stated that it has to be a common species and a specific bacterial strain within the species of previously confirmed health properties (Araya et al. 2002). To meet these requirements, it is fundamental to draw up a methodology of the molecular typing of the bacterial isolates belonging to the Lactobacillus genus since most strains with probiotic properties belong within this bacterial group.

The objective of this study is an attempt at standardization of the molecular methods of RAPD (Random Amplification of Polymorphic DNA), PFGE (Pulsed Field Gel Electrophoresis) and FISH (Fluorescence In Situ Hybridization) in the process of identification of the strains belonging to three species: Lactobacillus fermentum, L. gasseri and $L$. plantarum isolated from the human genital tract. Additionally, the MLST (Multilocus Sequence Typing) method was used for differentiation of $L$. plantarum strains. These three species are most often applied in probiotics preparations in combination with other bacteria or separately. The research has been conducted to enable the evaluation of the level of colonization of the genital tract by the examined probiotic strains belonging to the above-mentioned species in the 
physiological conditions as well as during clinical trials of the probiotic preparations.

\section{Materials and methods}

\section{Samples}

The examined strains came from a collection gathered during the period 2000 to 2005 at the Chair of Microbiology of the Jagiellonian University Medical College derived from the routine microbiological diagnostics of the female genital tract in 111 healthy women aged 18-45, carried out in our microbiology laboratory. The patients reported no infection that required treatment with antibiotics.

\section{Bacterial cultures}

Vaginal swabs were immediately cultured on Columbia blood agar (Oxoid) with 5\% sheep blood, de Man-Rogosa-Sharpe MRS agar (Oxoid), McConkey agar (Oxoid) and Schaedler agar (Oxoid). Aerobic bacteria were cultured in aerobic conditions at the temperature of $37^{\circ} \mathrm{C}$ for $24 \mathrm{~h}$ and anaerobes were cultured in an anaerobic chamber (MACS - MG 500 Work Station; DW Scientific) for $72 \mathrm{~h}$.

The cultivated colonies underwent routine identification for genus or species using Gram staining and API tests (bioMerieux). To identify Lactobacillus in the samples, the bacterial colonies were isolated from solid MRS agar and Schaedler agar. The single colonies of Lactobacillus morphology were isolated and were subsequently classified using phenotypic methods, i.e. Gram staining and API 50CHL (bioMerieux). The initial collection of 235 Lactobacillus isolates, which were obtained, was preliminarily classified at the species level. Afterwards, the presence of selected species, i.e. Lactobacillus fermentum, L. gasseri and L. plantarum, within the collection of isolates was conclusively confirmed with the use of the PCR method.

\section{DNA isolation}

The bacterial DNA was isolated with the application of a specialized kit for DNA extraction (Genomic Mini, DNA Gdansk). The isolation was carried out in accordance with the manufacturer's report.

\section{PCR species confirmation}

DNA amplification was conducted on the basis of the isolated DNA in order to determine the species affiliation of the tested bacterial isolates (Table 1) (Walter et al. 2000).

\section{Reference strains and Lactobacillus isolates}

The reference strains of the representatives of various bacterial species, which can appear in the genital tract, were used to conduct the specificity test of the FISH probes (Table 2). The reference strains belonging to the tested Lactobacillus species were used to verify whether the RAPD and PFGE methods allow differentiation among strains within each of the three examined bacterial species.

For FISH, RAPD and PFGE, 60 isolates of Lactobacillus, i.e. 20 isolates of each of the three studied species: L. fermentum, L. gasseri and L. plantarum, were used.

Fluorescence in situ hybridization (FISH)

Standardization of the FISH method was conducted on 60 isolates of lactobacilli. DNA LbpV3 probe sequences, specific for Lactobacillus plantarum, have been described in the literature (Ercolini et al. 2006). Because of this, only two probes for Lactobacillus fermentum and L. gasseri were designed in this study. The probe sequences were selected in such a way as to enable hybridization at the same temperature for all three probes, which allows typing of the examined Lactobacillus species in a single hybridization reaction with the use of a mixture of two or three probes. Designing the sequence of DNA probes consisted in the isolation of specific multiple nucleotide sequences located within the DNA coding of the bacterial 16S rRNA. Ribosomal Database Project II was used for this purpose (Loy et al. 2008). The probe sequences were selected in such a way that their species specificity should be preserved whereas the quantitative ratio of specific nucleotides should be at the level enabling the conducting of hybridization at the same temperature for both designed probes. The initially selected nucleotide sequences were checked for the species specificity for Lactobacillus gasseri and L. fermentum in the National Center for Biotechnology Information (NCBI) database with BLASTN software (Loy et al. 2008). The determined probe sequences were sent to the Eurobiotech Company for the synthesis of oligonucleotides which were additionally marked at the $5^{\prime}$ end with a red fluorescent (CY3) or green (Alexa488) dye (Eurobiotech). Afterwards, the specificity of the designed probes was examined on the reference strains and the gathered collection of isolates belonging to the three examined bacterial species was checked (Table 2) with the application of the procedure by Gosiewski et al. (2005). Bacterial cultures in $5 \mathrm{ml}$ liquid MRS were incubated during $24 \mathrm{~h}$ in the anaerobic conditions at $37^{\circ} \mathrm{C}$. Then, $0.5 \mathrm{ml}$ of cultures were transferred into $1 \mathrm{ml}$ of saline and mixed. The samples were centrifuged for $5 \mathrm{~min}$ at $8,000 \mathrm{~g}$. The pellet was carefully diluted in $20 \mu \mathrm{l}$ of sterile distilled water from which $10 \mu \mathrm{l}$ was transferred onto a SuperFrost ${ }^{\circledR}$ Plus (Menzel-Glaser) slide with a pipette for 
Table 1 Primers and PCR products for the three studied Lactobacillus species

\begin{tabular}{|c|c|c|c|c|}
\hline Species & Primer sequences & Primer & Target & PCR products \\
\hline L. fermentum & 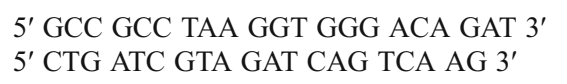 & $\begin{array}{l}\text { Lfpr } \\
\text { FermII }\end{array}$ & 16S-23S spacer & 200 and $400 \mathrm{bp}$ \\
\hline L. gasseri & $\begin{array}{l}5^{\prime} \text { GAG TGC GAG AGC ACT AAA G 3' } \\
5^{\prime} \text { CTA TTT CAA GTT GAG TTT CTC T 3' }\end{array}$ & $\begin{array}{l}\text { Gas I } \\
\text { Gas II }\end{array}$ & $16 \mathrm{~S}-23 \mathrm{~S}$ spacer & 300 and $500 \mathrm{bp}$ \\
\hline L. plantarum & $\begin{array}{l}5^{\prime} \text { GCC GCC TAA GGT GGG ACA GAT 3' } \\
5^{\prime} \text { TTA CCT AAC GGT AAA TGC GA 3' }\end{array}$ & $\begin{array}{l}\text { Lfpr } \\
\text { PlanII }\end{array}$ & 16S-23S spacer & 200 and $400 \mathrm{bp}$ \\
\hline
\end{tabular}

hybridization so as to obtain an examination area approximately $10 \mathrm{~mm}$ in diameter. The slide was dried under laminar flow. Subsequently, it was poured with $500 \mu \mathrm{l}$ of 4\% paraformaldehyde (Sigma) solution and incubated for $20 \mathrm{~min}$ at $4^{\circ} \mathrm{C}$. The specimen was then washed with PBS and 1-2 $\mathrm{ml}$ of $96 \%$ methanol (POCh) was poured over the slide. The whole specimen was incubated under the cover for $30 \mathrm{~min}$ at $-20^{\circ} \mathrm{C}$. On completion of the fixation process, methanol was washed off with warm $\left(50^{\circ} \mathrm{C}\right) \mathrm{PBS}$ and $20 \mu \mathrm{l}$ of diluted lysozyme $(1 \mathrm{mg} / \mathrm{ml})$ (Sigma) was placed on the slide. It was incubated for $5 \mathrm{~min}$ at $37^{\circ} \mathrm{C}$ and washed with warm PBS. Hybridization was performed with the use of the designed probes directed at the conservative fragment of 16S rRNA typical for Lactobacillus fermentum, L. gasseri and L. plantarum. To perform hybridization, $5 \mu \mathrm{l}$ of the examined probe solution $(50 \mathrm{ng} / \mu \mathrm{l})$ was mixed with $45 \mu \mathrm{l}$ of hybridization buffer ( $20 \mathrm{mM}$ Tris $\mathrm{HCl} ; 0.9 \mathrm{M} \mathrm{NaCl} ; 0.1 \%$ SDS; $\mathrm{pH}=7.2$ ), and heated to the temperature of approximately $50^{\circ} \mathrm{C}$. The prepared hybridization solution $(50 \mu \mathrm{l})$ was transferred onto the slide using an automatic pipette, and the whole preparation was placed in a moist chamber covered with an aluminium foil at the given temperature for $2 \mathrm{~h}$. Hybridization was conducted at temperatures ranging from 46 to $52^{\circ} \mathrm{C}$ in order to select the optimal one for all the three examined probes. Consequently, the specimen was washed with warm washing buffer (of the same composition as the hybridization buffer except for $0.1 \%$ SDS). The specimen was stained with DAPI at the concentration of $0.5 \mu \mathrm{l} / \mathrm{ml}$ (Sigma) for $5 \mathrm{~min}$ as well as carefully washed with sterile distilled water and dried in the dark. The slide was analyzed with the use of the Olympus BX51 fluorescence microscope and AnalySYS (Soft Imaging) software.

\section{Random amplification of polymorphic DNA (RAPD)}

Standardization of the RAPD method was performed on 60 bacterial isolates belonging to the above-mentioned three species, i.e. Lactobacillus fermentum, L. gasseri and L. plantarum, and confirmed with the PCR method. The test was performed with the application of Ready-To-Go RAPD
Table 2 Bacterial strains used in the specificity testing of the designed FISH probes

\begin{tabular}{llll}
\hline Strains & Tested probes & \\
\cline { 2 - 4 } & LFERM & LGASS & LbpV3 \\
\hline Lactobacillus fermentum DSM 20052 & + & - & - \\
L. fermentum isolates (no. 20) & + & - & - \\
Lactobacillus gasseri DSM 20243 & - & + & - \\
L. gasseri isolates (no. 20) & - & + & - \\
Lactobacillus plantarum ATCC 14431 & - & - & + \\
L. plantarum NCIMB 8825 & - & - & + \\
L. plantarum NCIMB 1406 & - & - & + \\
L. plantarum isolates (no. 20) & - & - & - \\
Lactobacillus johnsonii ATCC 33200 & - & - & - \\
Lactobacillus delbruecki subsp. lactis DSM 20072 & - & - & - \\
Lactobacillus acidophilus DSM 4356 & - & - & - \\
Streptococcus agalactiae DSM 2134 & - & - & - \\
Gardnerella vaginalis ATCC 14018 & - & - \\
Escherichia coli ATCC 25922 & - & - & - \\
Staphylococcus aureus ATCC 29213 & - & - \\
Bifidobacterium breve DSM 20213 & - & - \\
\hline
\end{tabular}


Analysis Kit (GE Healthcare). This kit contained five standard RAPD primers: primer no. 1: 5'-GGTGCGGGAA-3'; primer no. 2: 5'-GTTTCGCTCC-3'; primer no. 3: 5'-GTAGACCCGT-3'; primer no. 4: 5'-AAGAGCCCGT-3'; primer no. 5: 5'-AACGCGCAAC-3'. Standardization of the RAPD method consisted in testing five primers and selecting the most discriminative one for the strains within the species of Lactobacillus fermentum, L. gasseri and L. plantarum.

The detailed protocol for RAPD was provided by the manufacturer of the kit. After DNA amplification, high resolution electrophoresis $(1.5 \mathrm{~h} ; 5 \mathrm{~V} / \mathrm{cm})$ in $8 \%$ polyacrylamide gel (Sigma) was applied. Electrophoresis was carried out with the use of PROTEAN II (BioRad) in the presence of ethidium bromide of the concentration of $0.25 \mu \mathrm{l} / \mathrm{ml}$ (Sigma). The obtained image was processed with the application of QuantityOne (BioRad) software and GelDoc 2000 (BioRad) apparatus.

\section{Pulsed field gel electrophoresis (PFGE)}

Standardization of the method was conducted on 60 isolates belonging to the three Lactobacillus species. Standardization of the PFGE method consisted in selecting the appropriate restriction enzyme as well as establishing the optimal parameters of electrophoretic separation, such as duration and the electrical pulse which were the most discriminative for strains within the three species.

The examined isolates were prepared according to the Tynkkynen et al. (1999). Single bacterial colonies of Lactobacillus were cultured in the liquid MRS (Oxoid) with the addition of $1 \%$ glycine (Sigma) and $0.25 \%$ threonine (Sigma). Subsequently, the incubation was carried out for $24 \mathrm{~h}$ in anaerobic conditions at $37^{\circ} \mathrm{C}$. Cultured lactobacilli were centrifuged (approximately $500 \mu \mathrm{l}$ of culture medium) for $5 \mathrm{~min}$ at $8,000 \mathrm{~g}$. The pellet was washed with $1 \mathrm{ml}$ of WB1 buffer $\left(10 \mathrm{mM}\right.$ Tris; $20 \mathrm{mM} \mathrm{NaCl} ; 50 \mathrm{mM} \mathrm{EDTA}_{2} \mathrm{Na}$; $\mathrm{pH}=$ 7.2), and afterwards diluted in $150 \mu \mathrm{l}$ of WB1 buffer. The obtained suspension was heated at the temperature of $50^{\circ} \mathrm{C}$ in the thermoblock and then $150 \mu \mathrm{l}$ of $2 \%$ LMP agarose (Clean Cut BioRad) was added. The mixture was poured into Plug Mold (BioRad) to form blocks and cooled for $10 \mathrm{~min}$ at $4^{\circ} \mathrm{C}$ to allow the agarose to solidify. The blocks were placed in sterile 2.0-ml Eppendorf tubes containing $500 \mu \mathrm{l}$ of LB1 lysis buffer (6 mM Tris; $1 \mathrm{M} \mathrm{NaCl} ; 100$ mM EDTA ${ }_{2} \mathrm{Na} ; 1 \%$ SDS; $0.2 \%$ deoxycholate; $\mathrm{pH}=7.6$ ) with the addition of $2.5 \mathrm{mg} / \mathrm{ml}$ of lysozyme (Sigma) and $20 \mathrm{U}$ of mutanolysin (Sigma). The blocks were incubated for $16 \mathrm{~h}$ at $37^{\circ} \mathrm{C}$. On completion of the incubation, LB1 was removed and blocks were washed with WB1 $(1 \mathrm{ml})$. Afterwards, $500 \mu \mathrm{l}$ of LB2 $(100 \mathrm{mM}$ EDTA $_{2} \mathrm{Na} ; 1 \% \mathrm{SDS} ; 0.2 \%$ deoxycholate $\mathrm{pH}=8.0$ ) was added with the addition of $1 \mathrm{mg} / \mathrm{ml}$ proteinase $\mathrm{K}$ (Applichem). The blocks were incubated for $\mathrm{t} 16 \mathrm{~h}$ at $50^{\circ} \mathrm{C}$. On completion of the enzymatic digestion phase, the blocks were washed with $1 \mathrm{ml}$ of WB2 (20 mM Tris; $\left.50 \mathrm{mM} \mathrm{EDTA}{ }_{2} \mathrm{Na} ; \mathrm{pH}=8.0\right)$ for $30 \mathrm{~min}$. The process of washing was repeated three times. Later, the blocks were washed twice with TE buffer $(10 \mathrm{mM}$ Tris $\mathrm{HCl} ; 1 \mathrm{mM} \mathrm{EDTA}_{2} \mathrm{Na} ; \mathrm{pH}=8.0$ ) for $30 \mathrm{~min}$. After TE buffer was removed, the blocks were transferred to new sterile Eppendorf $(1.5 \mathrm{ml})$ tubes containing $500 \mu \mathrm{l}$ of $1 \times$ concentrated buffer for the restriction enzyme selected for the specific Lactobacillus species. The blocks were incubated in the buffer at room temperature for $1 \mathrm{~h}$. Afterwards, the buffer was drained off and again $300 \mu$ of the same buffer was added as well as $25 \mathrm{U}$ of one of the tested restriction enzymes: SfiI, SmaI, NotI, SgsI (Fermentas). Restriction digestion was carried out in the thermoblock for $16 \mathrm{~h}$ at the temperature optimal for the applied restriction enzyme (producer's recommendations). On completion of the digestion process, the blocks were placed in the wells in $1 \%$ agarose gel for PFGE (BioRad). The gel underwent the pulsed electrophoresis pursuant to the individually tested parameters for the examined Lactobacillus species. The electrophoresis was conducted in CHEF-DR III (BioRad) apparatus at $14^{\circ} \mathrm{C}$. After the process of electrophoresis, the gel was stained in water for $20 \mathrm{~min}$ in the presence of ethidium bromide at the concentration of $0.25 \mu \mathrm{l} / \mathrm{ml}$ (Sigma). The obtained image was processed with the application of QuantityOne (BioRad) software and GelDoc 2000 (BioRad) apparatus. Comparative analysis of the obtained genetic profiles of the examined isolates was performed with the use of Molecular Analyst (Applied Maths) software.

\section{Multilocus sequence typing (MLST)}

Analysis of 60 isolates of Lactobacillus plantarum strains using the MLST method was carried out in accordance with the methodology developed by de las Rivas et al. (2006). DNA sequencing of six housekeeping genes ( $g d h$, glutamate dehydrogenase; gyrB, DNA gyrase B subunit; $d d l$, Dalanine ligase; $m u t S$, DNA mismatch repair protein; purK1, phosphocarboxylase; pgm, phosphoglucomutase) was done by GENOMED. Analysis of received DNA sequences was performed using computer programs ChromasPro 1.5 (Digital River). The dendrograms were prepared using Molecular Evolutionary Genetics Analysis MEGA v.3.1 (http:// www.megasoftware.net).

\section{Results}

In the collection of 235 isolates belonging to Lactobacillus genus, their species affiliation was confirmed with the use of API 50CHL tests. Approximately 2.12 isolates representing different species were found in one patient. They belonged to the following species: Lactobacillus gasseri, L. crispatus, L. acidophilus, $L$. johnsonii, L. fermentum, $L$. plantarum, $L$. 
rhamnosus, L. delbrueckii and L. brevis. Detailed results are presented in an earlier publication of Strus et al. (2006).

All Lactobacillus fermentum, L. gasseri and L. plantarum isolates were selected for further analysis and their taxonomic verification was performed with the application of the PCR method. For standardization of RAPD, PFGE and FISH methods, 60 isolates belonging to the three mentioned Lactobacillus species were chosen.

The following two probes: LFERM 5' CGT CAA CGT ATG AAC AGT 3', LGASS 5' TTT TAA ACT CTA GAC ATG 3' were designed. The specificity of the planned probes and the probe LbpV3 5' CCG TCA ATA CCT GAA CAG 3' (Ercolini et al. 2006) was tested on the examined reference strains representing the species appearing in the female genital tract and within the gathered collection of 60 isolates belonging to the three studied Lactobacillus species (Table 2). Furthermore, the probes were also tested on the mixtures consisting of two different Lactobacillus species to confirm their species affiliation. After the conducted hybridization, it was proved that the designed probes were species specific and the process of hybridization should be carried out at $48^{\circ} \mathrm{C}$, which was optimal for the three examined probes (Fig. 1).

For each of the Lactobacillus species examined with the RAPD method, the most discriminative primer from the Ready-To-Go RAPD kit was selected. For Lactobacillus fermentum and L. gasseri strains, it was primer no. 5, whereas for L. plantarum it was primer no. 2 (Fig. 2). The choice of primers was made on the basis of the RAPD typing performed for 20 Lactobacillus isolates of the three examined species as well as the reference strains. It was proved that the RAPD method allowed for merely insignificant discrimination of Lactobacillus fermentum isolates. Furthermore, no discrimination was possible among L. gasseri isolates - only the reference strain DSM 20243 was different from the remaining ones (Fig. 2). In the group of Lactobacillus plantarum isolates, it was demonstrated that
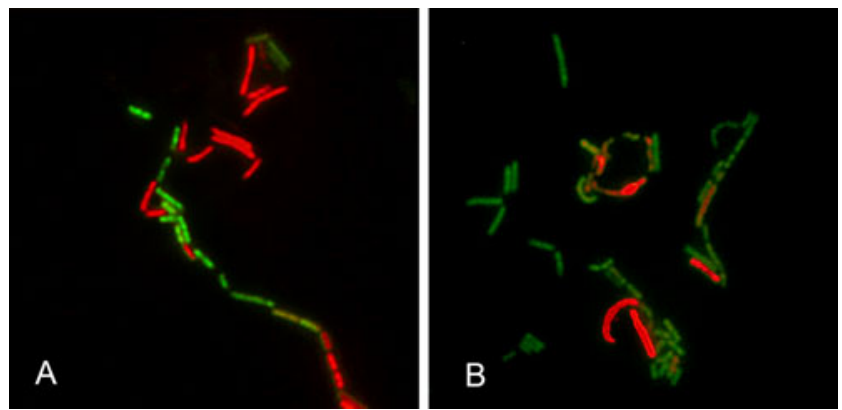

Fig. 1 Application of the FISH method; magnification $\times 1,000$. a Lactobacillus fermentum labeled with FERM-CY3 probe (red fluorescence) and L. plantarum labeled with LabV3-Alexa488 probe (green fluorescence). b $L$. gasseri labeled with LGASS-CY3 probe (red fluorescence) and L. plantarum labeled with LabV3-Alexa488 probe (green fluorescence) the applied RAPD primers could not discriminate the examined strains of human origin, only the reference plant strains displayed a small degree of variation of genetic markers (Fig. 2).

For the purpose of standardization and improvement of the PFGE method, for each Lactobacillus species, the appropriate restriction enzyme and the most optimal conditions for electrophoresis were selected (Table 3 ) in order to obtain readable band profiles, suitable for specifying the level of genetic relatedness and conclusive for differentiation of the examined isolates. For the species belonging to Lactobacillus fermentum, out of the four tested restriction enzymes (SfiI, SmaI, NotI, SgsI), the best-quality restriction profiles were obtained using SgsI digestion. For Lactobacillus gasseri, it was the SmaI restriction enzyme (Fig. 3, Table 3). For collection of isolates belonging to Lactobacillus plantarum species, similarly to the RAPD method, it was impossible to display genetic variation among the strains derived from the human genital tract despite testing three restriction enzymes (SfiI, SgsI and NotI) and obtaining good quality electrophoretic results (Table 3 ). Different genotypes were confirmed exclusively for the reference strains originating from plants. Analogous results of Lactobacillus plantarum strains genotyping were obtained with the use of the MLST method. The outcome of sequencing six housekeeping genes $(g d h, g y r B, d d l, m u t S$, purK1, pgm) indicates $100 \%$ genetic similarity of the examined strain collection of human origin. Only the strains of plant origin are heterogeneous (Fig. 4).

\section{Discussion}

Methodology of the molecular typing of the bacterial strains and species was developed mainly in order to create more and more effective tools useful in the microbiological diagnostics of pathogens as well as in the molecular epidemiology. Currently, when the interest in probiotics is increasing, there is a need to apply the methods of molecular biology in genotyping of probiotic microorganisms. However, there exists a lack of applications of generally accepted methods, such as RAPD or PFGE, for these bacteria. Standardization of these methods for specific Lactobacillus species constituting the reservoir of probiotic strains will allow conducting research on colonization by the above-mentioned species. The application of classical methods of bacterial identification based on the phenotypic characteristics, such as the API 50CHL test, is quite insufficient. Boyd et al. (2005) have demonstrated in their studies that the API 50 CHL test enabled the correct species identification of a mere 4 isolates, taking into account that a total of 90 were isolated from the female genital tracts of the examined patients. The methods based on the phenotypic evaluation of bacteria 
Fig. 2 Results of genotyping the bacterial isolates obtained after the reaction of RAPD with primer no. 5 , for isolates of Lactobacillus fermentum ( $L f$ ) (a), and L. gasseri $(L g)(\mathbf{b})$ species, as well as with primer no. 2 for $L$. plantarum $(L p)$ (c) species. The identical band profiles for L. plantarum of human origin are visible on the gel; the reference strains of plant origin with various genetic profiles are displayed in the frame
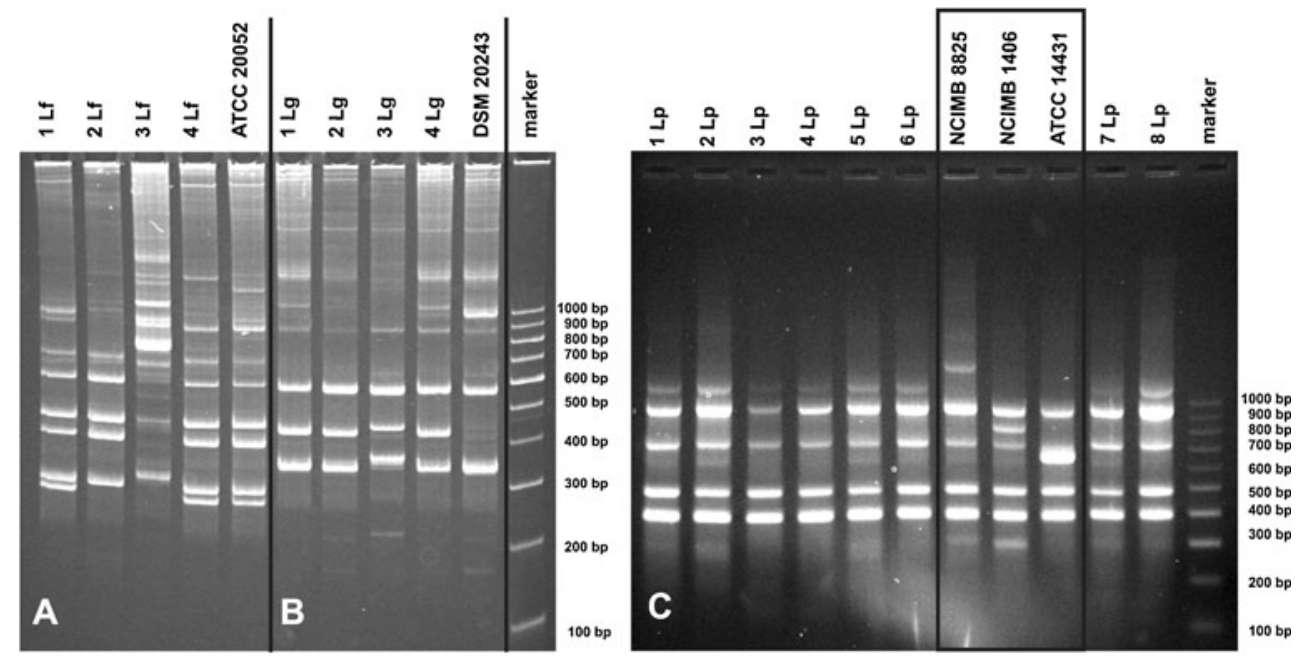

depend on numerous external factors, such as changes of the environmental factors in the culture (Nigatu 2000; van Belkum et al. 2007). The application of methods based on the analysis of nucleic acids was necessary since this allowed the precise identification of Lactobacillus species supported by stable genetic markers, such as the conservative sequences of 16S rRNA (Walter et al. 2000; Dimitonova et al. 2008).

LFERM, LGASS and LPLAN probes enabled the specific detection of Lactobacillus fermentum, L. gasseri and $L$. plantarum species with the use of the FISH method on the bacterial cultures. Probe sequences were designed in such a way as to allow hybridization at the same temperature $\left(48^{\circ} \mathrm{C}\right)$ for all three probes, which enabled the detection of the bacteria belonging to the three examined species in a single sample. The designed probes may also be used to detect the bacteria using the direct samples collected from the female genital tract. Such an application of the FISH method has been presented by Strus et al. (2009) as well as by Fredricks et al. (2005) for detection of pathogenic vaginal bacteria. Moreover, it has also been described in microbiology for identification of closely related species of pathogenic microorganisms (Burrell et al. 2004; Brzychczy-Włoch et al. 2008).

Within the specific Lactobacillus species, one can differentiate the strains possessing their characteristic genetic markers. This study presents an endeavor at working out the technique for genotyping the bacterial strains of Lactobacillus fermentum, L. gasseri and L. plantarum isolated from the female genital tract with the use of the RAPD and PFGE methods. The RAPD method, which was cheaper and easier to apply, did not provide repeatable results. Additionally, it demonstrated a lower degree of differentiation among the examined strains of Lactobacillus fermentum and $L$. gasseri than the PFGE method. For Lactobacillus plantarum isolates, it was impossible to demonstrate genetic differences among the strains isolated from the human genital tract. The obtained results confirm the low efficiency of the RAPD method for differentiating the strains belonging to the three examined species, particularly Lactobacillus plantarum. However, the L. plantarum strains of plant origin demonstrate effective differentiation (Elegado et al. 2004).

Table 3 PFGE standardization for the three studied Lactobacillus species

\begin{tabular}{llll}
\hline Species & Restriction enzymes & Optimal conditions for electrophoretic separation & Result \\
\hline L. fermentum & SfiI & pulses: $5.0-45 \mathrm{~s} ; 5.0 \mathrm{~V} / \mathrm{cm} ; 22 \mathrm{~h}$ & Very small restriction fragments below $97 \mathrm{~kb}$ \\
& Not $\mathrm{I}$ & pulses: $1.0-40 \mathrm{~s} ; 6.0 \mathrm{~V} / \mathrm{cm} ; 22 \mathrm{~h}$ & Very small restriction fragments below $97 \mathrm{~kb}$ \\
& $S m a \mathrm{I}$ & pulses: $0.1-6.0 \mathrm{~s} ; 4.5 \mathrm{~V} / \mathrm{cm} ; 22 \mathrm{~h}$ & Very small restriction fragments below $97 \mathrm{~kb}$ \\
& SgsI & pulses: $1.0-25 \mathrm{~s} ; 5.5 \mathrm{~V} / \mathrm{cm} ; 24 \mathrm{~h}$ & Optimal bands distribution on gel \\
L. gasseri & SmaI & pulses: $3.0-13 \mathrm{~s} ; 5.0 \mathrm{~V} / \mathrm{cm} ; 22 \mathrm{~h}$ & Optimal bands distribution on gel \\
L. plantarum & SfiI & pulses: $1.0-20 \mathrm{~s} ; 4.5 \mathrm{~V} / \mathrm{cm} ; 26 \mathrm{~h}$ & Optimal bands distribution on gel \\
& NotI & pulses: $1.0-15 \mathrm{~s} ; 6.0 \mathrm{~V} / \mathrm{cm} ; 24 \mathrm{~h}$ & Small restriction fragments below $145 \mathrm{~kb}$ \\
& $S g S \mathrm{I}$ & pulses: $1.0-25 \mathrm{~s} ; 5.5 \mathrm{~V} / \mathrm{cm} ; 24 \mathrm{~h}$ & Optimal bands distribution on gel \\
\hline
\end{tabular}


Fig. 3 Results of genotyping the bacterial isolates with the use of the optimized PFGE method. a Lactobacillus fermentum $(L f)(S g s I$ restriction enzyme); b $L$. gasseri $(L g)$

(SmaI restriction enzyme) and $\mathbf{c}$

L. plantarum $(\mathrm{Lp})(\mathrm{SgsI}$ |restriction enzyme) $\begin{array}{lllllll}40 & 50 & 60 & 70 & 80 & 90 & 100\end{array}$

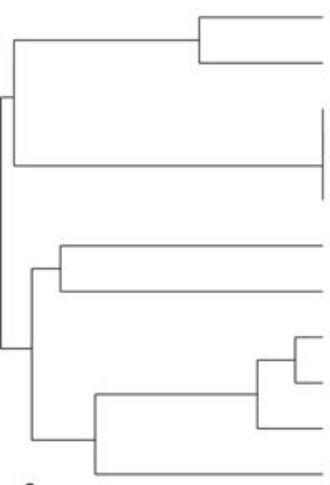

A

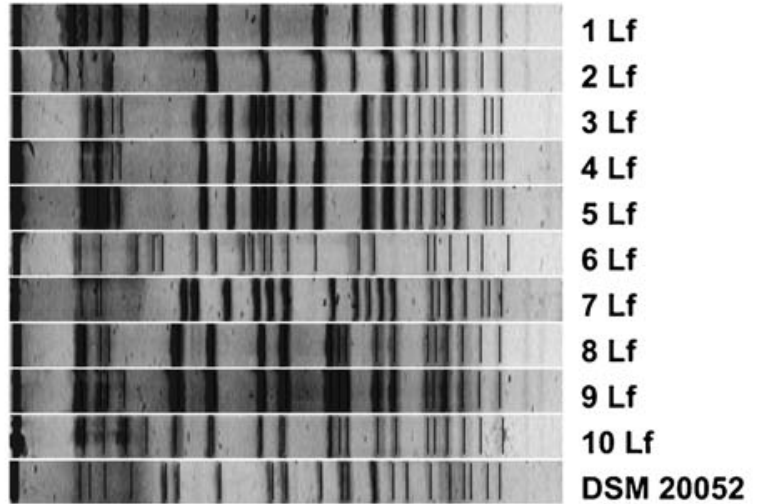

11 entries Bands, Jaccard (Tol 2,0\%, Opt 0,50\%, Min area 0,0\%) [1-400] UPGMA

$\begin{array}{lllll}60 & 70 & 80 & 90 & 100\end{array}$

B

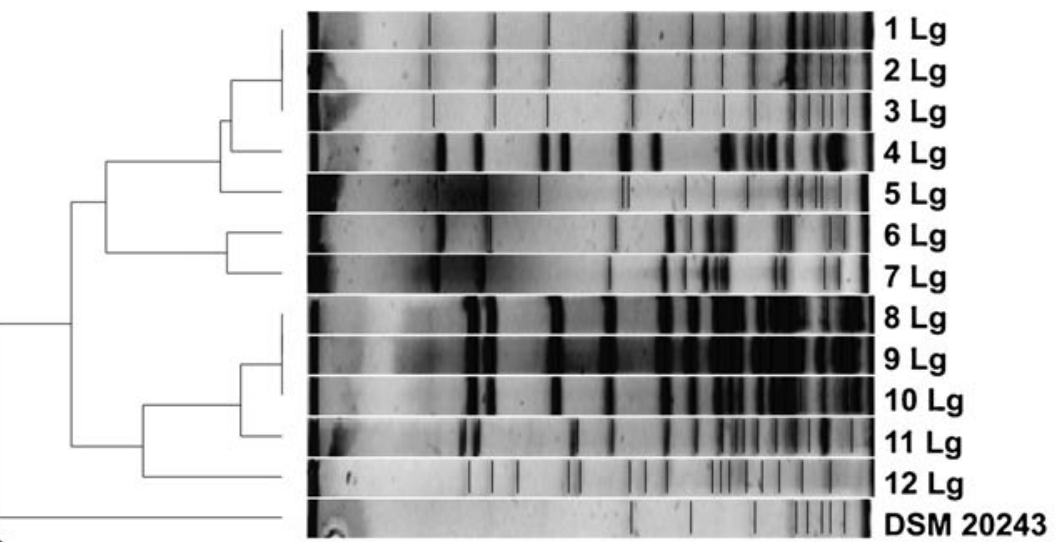

13 entries Bands, Jaccard (Tol 2,0\%, Opt 0,50\%, Min area 0,0\%) [1-400] UPGMA
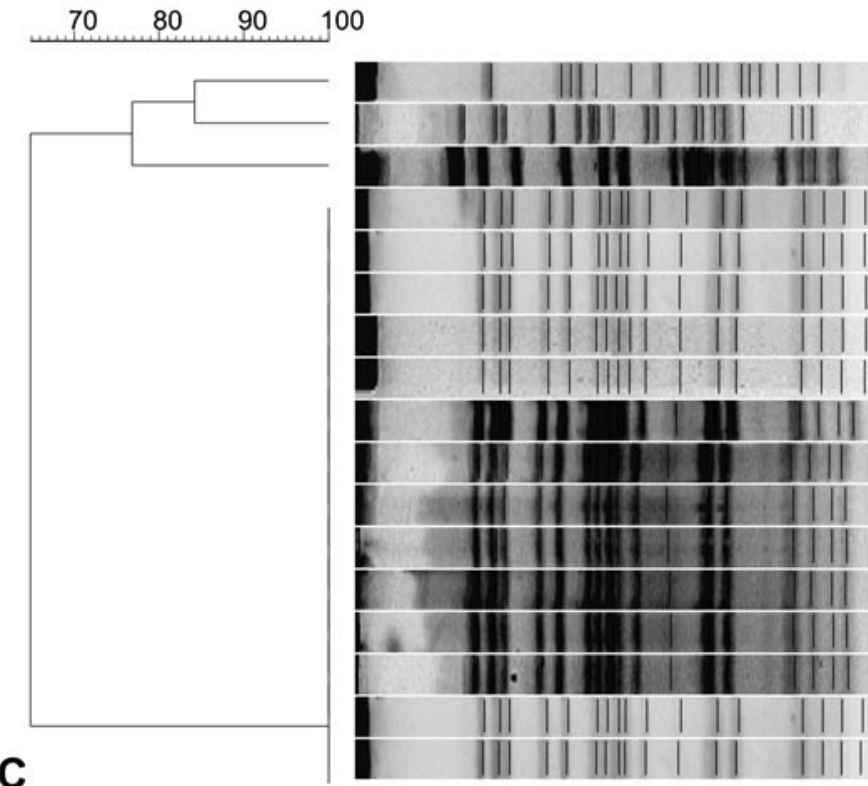

ATCC14431

NCIMB8825

NCIMB 1406

$1 \mathrm{Lp}$

$2 \mathrm{Lp}$

3 Lp

4 Lp

$5 \mathrm{Lp}$

$6 \mathrm{Lp}$

$7 \mathrm{Lp}$

$8 \mathrm{Lp}$

$9 \mathrm{Lp}$

$10 \mathrm{Lp}$

$11 \mathrm{Lp}$

$12 \mathrm{Lp}$

13 Lp

$14 \mathrm{Lp}$

17 entries Bands, Jaccard (Tol 2,0\%, Opt 0,50\%, Min area 0,0\%) [1-400] UPGMA 
Fig. 4 Results of genotyping of the Lactobacillus plantarum $(L p)$ isolates obtained from the MLST method. a the genetic similarity within $g d h$ housekeeping gene; $\mathbf{b}$ the genetic similarity within purK housekeeping gene

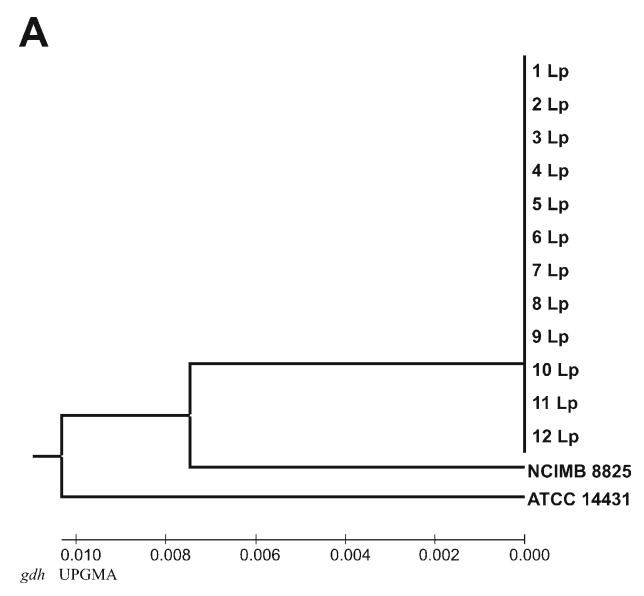

We cannot exclude that the universal primers applied, included in the Ready-To-Go RAPD Analysis Kit, did not allow the obtaining of a higher level of differentiation among the strains. On the other hand, a lower efficiency of the RAPD method as compared to the PFGE method was frequently presented by other authors for numerous bacterial genera and species (Seo et al. 2006; Stakenborg et al. 2006; Pingault et al. 2007). Contrary to the RAPD method, PFGE enabled the obtaining of repeatable results and demonstrated a higher discriminative power than RAPD, which was, as a matter of fact, confirmed during genotyping the pathogenic bacteria by other authors (Löfström et al. 2006; Ostojić 2008). The PFGE method is described as the "golden standard" in bacterial genotyping, yet its applications for probiotic bacteria are still limited. The most significant differences in developing the PFGE methodology were created by Lactobacillus fermentum isolates. The starting point was the study by Hautefort et al. (1999) who carried out PFGE genotyping with the use of the NotI enzyme. The conducted PFGE genotyping according to Hautefort's procedure revealed that the obtained band profiles consisted of too many small restriction fragments, which effectively prevented differentiation among the examined isolates due to overlapping. Subsequently, three restriction enzymes were selected and tested experimentally determining their electrophoretic parameters. For SmaI and SfiI enzymes, similarly to NotI, the obtained band patterns were inadequate for analysis. Conclusively, the application of $S g s \mathrm{I}$ enzyme and optimized separation parameters enabled obtaining good quality restriction patterns suitable for further analysis of genetic differentiation of Lactobacillus fermentum species.

For Lactobacillus gasseri isolates, the SmaI enzyme was selected which allowed the obtaining of a good quality restriction pattern on the gel. The selection of this restriction enzyme as optimal for $L$. gasseri isolates genotyping was confirmed by Kawase et al. 2011. To conduct the genetic differentiation among Lactobacillus plantarum strains with the use of the PFGE method, the procedure by Ventura et al. (2003) as well as the Sfi enzyme were applied with the simultaneous modification of the voltage from 6 to $4.5 \mathrm{~V} / \mathrm{cm}$ and prolonging the time of electrophoretic separation from 18 to $26 \mathrm{~h}$ to obtain a better quality separation on the gel. Consequently, two successive restriction enzymes were selected and tested: NotI and SgsI establishing the optimal PFGE parameters in an experimental way. Unfortunately, despite the application of three different restriction enzymes, similarly to the analysis with the use of the RAPD method, it was impossible to provide the genetic differences among the examined isolates derived from the female genital tract, with only the reference strains of plant origin displaying genetic variability. The application of the MLST method also failed to differentiate the studied collection of Lactobacillus plantarum isolates of human origin; analogous to PFGE and RAPD methods, only the strains of plant origin were different in terms of genetics. Similar homogeneity of the isolates of L. plantarum originating from wine fermentation was presented by Spano et al. (2002) with the application of the RAPD method. Possibly, within the Lactobacillus plantarum species, we may deal with a very rare microbiological phenomenon of forming the genetically stable clones, what was described by Tanganurat et al. (2009) and Markiewicz et al. (2010).

This research conducted on the application of genotyping methods will enable the carrying out of studies concerning the colonization of the female genital tract by probiotic bacteria belonging to Lactobacillus fermentum and L. gasseri. What is more, the research results can be applied to directly detect these species in the vagina with the use of the FISH method. As regards the bacteria belonging to the Lactobacillus plantarum species, it is necessary to select a particular strain which possesses specific genetic markers enabling its differentiation from commonly occurring representatives of a genetically stable clone. It is conceivable, too, that one has to make use of other available methods of 
genotyping, such as MLVA (Multiple Locus Variable number tandem repeat Analysis) or whole bacteria genome sequencing.

Acknowledgement This work has been financed from the grant of the Jagiellonian University Medical College.

Open Access This article is distributed under the terms of the Creative Commons Attribution Noncommercial License which permits any noncommercial use, distribution, and reproduction in any medium, provided the original author(s) and source are credited.

\section{References}

Araya M, Morelli L, Reid G, Sanders ME, Stanton C, Pineiro M, Ben Embarek P (2002) Guidelines for the Evaluation of Probiotics in Food. FAO/WHO, Ontario, Canada

Boyd MA, Antonio MA, Hillier SL (2005) Comparison of API $50 \mathrm{CH}$ strips to whole-chromosomal DNA probes for identification of Lactobacillus species. J Clin Microbiol 43:5309-5311

Brzychczy-Włoch M, Strus M, Pawlik D, Gosiewski T, Krzysztof R, Drzewiecki A, Lauterbach R, Heczko PB (2008) Studies on the possible application of molecular methods in diagnosing carriers and in similarity analysis of group B streptococci (Streptococcus agalactiae). Med Dosw Mikrobiol 60:91-99

Burrell PC, O'Sullivan C, Song H, Clarke WP, Blackall LL (2004) Identification, detection, and spatial resolution of Clostridium populations responsible for cellulose degradation in a methanogenic landfill leachate bioreactor. Appl Environ Microbiol 70:2414 2419

de las Rivas B, Angela Marcobal A, Rosario Munoz R (2006) Development of a multilocus sequence typing method for analysis of Lactobacillus plantarum strains. Microbiology 152:85-93

Dimitonova SP, Bakalov BV, Aleksandrova-Georgieva RN, Danova ST (2008) Phenotypic and molecular identification of lactobacilli isolated from vaginal sretions. J Microbiol Immunol Infect 41:469-477

Elegado FB, Guerra MA, Macayan RA, Mendoza HA, Lirazan MB (2004) Spectrum of bacteriocin activity of Lactobacillus plantarum BS and fingerprinting by RAPD-PCR. Int J Food Microbiol 95:11-18

Ercolini D, Villani F, Aponte M, Mauriello G (2006) Fluorescence in situ hybridisation detection of Lactobacillus plantarum group on olives to be used in natural fermentations. Int J Food Microbiol 112:291-296

Fredricks DN, Fiedler TL, Marrazzo JM (2005) Molecular identification of bacteria associated with bacterial vaginosis. N Engl J Med 353:1899-1911

Gosiewski T, Kasprzyk A, Strus M (2005) Comparision of the sensitivity of detection of bacteria in human blood using classic culture methods and molecular techniques: PCR and FISH. Med Dosw Mikrobiol 57:319-325

Hautefort I, Roels A, Tailliez P, Ladiré M, Raibaud P, Ducluzeau R, Fons M (1999) Selection of Lactobacillus fermentum strains able to durably colonize the digestive tract of mice harboring a complex human flora. FEMS Microbiol Ecol 29:23-31

Kawase M, He F, Kubota A, Miyazawa K, Yoda K, Hiramatsu M (2011) Strain-specific detection by pulsed-field gel electrophoresis of Lactobacillus gasseri TMC0356 in human feces after oral administration of these organisms. Microbiol Immunol 55:589-594
Löfström C, Eriksson J, Aspán A, Häggblom P, Gunnarsson A, Borch $\mathrm{E}$, Rådström $\mathrm{P}$ (2006) Improvement and validation of RAPD in combination with PFGE analysis of Salmonella enterica ssp. enterica serovar Senftenberg strains isolated from feed mills. Vet Microbiol 114:345-351

Loy A, Arnold R, Tischler P, Rattei T, Wagner M, Horn M (2008) probeCheck-a central resource for evaluating oligonucleotide probe coverage and specificity. Environ Microbiol 10:2894-2898

Markiewicz LH, Biedrzycka E, Wasilewska E, Bielecka M (2010) Rapid molecular identification and characteristics of Lactobacillus strains. Folia Microbiol 55:481-488

Nigatu A (2000) Evaluation of numerical analyses of RAPD and API $50 \mathrm{CH}$ patterns to differentiate Lactobacillus plantarum, Lact. fermentum, Lact. rhamnosus, Lact. sake, Lact. parabuchneri, Lact. gallinarum, Lact. casei, Weissella minor and related taxa isolated from kocho and tef. J Appl Microbiol 89:969-978

Ostojić M (2008) Epidemiologic genotyping of methicillin-resistant Staphylococcus aureus (MRSA) by pulsed-field gel electrophoresis (PFGE). Bosn J Basic Med Sci 8:259-265

Pingault NM, Lehmann D, Bowman J, Riley TV (2007) A comparison of molecular typing methods for Moraxella catarrhalis. J Appl Microbiol 103:2489-2495

Seo YS, Lee SH, Shin EK, Kim SJ, Jung R, Hahn TW (2006) Pulsed-field gel electrophoresis genotyping of Salmonella gallinarum and comparison with random amplified polymorphic DNA. Vet Microbiol 115:349-357

Spano G, Beneduce L, Tarantino D, Zapparoli G, Massa S (2002) Characterization of Lactobacillus plantarum from wine must by PCR species-specific and RAPD-PCR. Lett Appl Microbiol $35: 370-374$

Stakenborg T, Vicca J, Maes D, Peeters J, de Kruif A, Haesebrouck F, Butaye P (2006) Comparison of molecular techniques for the typing of Mycoplasma hyopneumoniae isolates. J Microbiol Methods 66:263-275

Strus M, Brzychczy-Włoch M, Gosiewski T, Kochan P, Heczko PB (2006) The in vitro effect of hydrogen peroxide on vaginal microbial communities. FEMS Immunol Med Microbiol 48:56-63

Strus M, Pawlik D, Brzychczy-Wloch M, Gosiewski T, Rytlewski K, Lauterbach R, Heczko PB (2009) Group B streptococcus colonization of pregnant women and their children observed on obstetric and neonatal wards of the University Hospital in Krakow, Poland. J Med Microbiol 58:228-233

Tanganurat W, Quinquis B, Leelawatcharamas V, Bolotin A (2009) Genotypic and phenotypic characterization of Lactobacillus plantarum strains isolated from Thai fermented fruits and vegetables. $\mathrm{J}$ Basic Microbiol 49:377-385

Tynkkynen S, Satokari R, Saarela M, Mattila-Sandholm T, Saxelin M (1999) Comparison of ribotyping, randomly amplified polymorphic DNA analysis, and pulsed-field gel electrophoresis in typing of Lactobacillus rhamnosus and Lactobacillus casei strains. Appl Environ Microbiol 65:3908-3914

van Belkum A, Tassios PT, Dijkshoorn L, Haeggman S, Cookson B, Fry NK, Fussing V, Green J, Feil E, Gerner-Smidt P, Brisse S, Struelens M (2007) Guidelines for the validation and application of typing methods for use in bacterial epidemiology. Clin Microbiol Infect 13:1-46

Ventura M, Canchaya C, Kleerebezem M, de Vos WM, Siezen RJ, Brüssow H (2003) The prophage sequences of Lactobacillus plantarum strain WCFS1. Virology 316:245-255

Walter J, Tannock GW, Tilsala-Timisjarvi A, Rodtong S, Loach DM, Munro K, Alatossava T (2000) Detection and identification of gastrointestinal Lactobacillus species by using denaturing gradient gel electrophoresis and species-specific PCR primers. Appl Environ Microbiol 66:297-303 